MSC 74G55

\title{
Uniqueness solution to the inverse spectral problem with distributed parameters on the graph-star*
}

\author{
A. P. Zhabko ${ }^{1}$, K. B. Nurtazina ${ }^{2}$, V. V. Provotorov ${ }^{3}$ \\ 1 St. Petersburg State University, 7-9, Universitetskaya nab., St. Petersburg, \\ 199034, Russian Federation \\ 2 N. Gumilyov Eurasian National University, 2, ul. Satpaeva, Nur-Sultan, \\ 010008, Republic Kazakhstan \\ 3 Voronezh State University, 1, Universitetskaya pl., Voronezh, \\ 394006, Russian Federation
}

For citation: Zhabko A. P., Nurtazina K. B., Provotorov V. V. Uniqueness solution to the inverse spectral problem with distributed parameters on the graph-star. Vestnik of Saint Petersburg University. Applied Mathematics. Computer Science. Control Processes, 2020, vol. 16, iss. 2, pp. 129-143. https://doi.org/10.21638/11701/spbu10.2020.205

In the space of piecewise smooth functions on a star graph, the question of the uniqueness of the recovery of the differential operator of a boundary value problem from its spectral characteristics is analyzed. The uniqueness of the recovery of the coefficient in a differential expression and the constant in the boundary conditions of a boundary value problem from spectral data is considered - a set of eigenvalues and a set of norms of the operator's eigenfunctions. The operator of the boundary value problem has a singularity generated by the structure of the graph: differential expression is defined on the interior parts of all the edges of the graph, and in the interior node of the graph, where the differential expression loses its meaning, there is a generalized condition of Kirchhoff - the condition of agreement (the condition of conjugating). A spectral approach is used, which is based on the spectral properties of the elliptical operator: the analyticity of Green's function of the boundary value problem on the spectral parameter, spectral completeness and the basis property of the set of its eigenfunctions in the space of square integrable function. The results are the basis for solving inverse problems for evolutionary differential systems of parabolic and hyperbolic types with distributed parameters on the network (graph), the elliptical part of which contains coefficients to be determined. In problems of an applied nature, these are, first of all, parameters that characterize the properties of the transfer of the solid environment and describe the elastic properties of the process of deformation of the environment. The approach mentioned above can also be applied to problems whose space variable is vectorlike and varies in a network-like domain.

Keywords: graph, differential operator, spectral characteristics, inverse spectral problem, uniqueness solution.

Introduction. When studying the questions of the identification of heat-physical or elastic characteristics of network-like industrial objects, one of the most important problem is to identify unknown coefficients in the evolutionary differential equation, describing the process of heat transfer or wave process in the considered constructions [1-6]. Within the mathematical models of these processes, this problem is drawn up in the form of a inverse problem of determining the coefficients of the evolutionary differential equation along known data on the observed states of the process or other a priori information

* This work was financially supported by the Ministry of Education and Science of the Republic Kazakhstan (project N AP05136197).

(C) Санкт-Петербургский государственный университет, 2020 
(data of transmitters fixing the states of the process or some of its manifestations). In case, where the differential equation coefficients depend only on the space variable, we naturally come to analyze the inverse spectral problem of the Sturm-Liouville type, based on the spectral properties of the elliptical operator for the evolutionary equation with the distributed parameters on the graph $[2,4,7,8]$. In this case, the input information for the inverse problem is spectral data: a set of eigenvalues and a set of norms of eigenfunctions.

Below are the conditions of the uniqueness of the inverse spectral problem of the Sturm-Liouville type with distributed parameters on the graph-star and recommendations given for the case of analysis of the inverse spectral problem on the graph-tree.

Setting of a problem, the basic statement. We adhere to the concepts and designations accepted in the works [9-12], and as well use statement of work $[9,11,12]$, touching upon the spectral properties of a elliptical operator with distributed parameters on a graph-star.

We denote by $\Gamma$ a geometric graph-star with ribs $\gamma_{k}(k=\overline{1, m})$ and a node $\xi$. Each edge $\gamma_{k}(k=\overline{1, m-1})$ is parameterized by a section $[0, \pi / 2]$ and edge $\gamma_{m}$ is parameterized by a section $[\pi / 2, \pi]$, in addition, the orientation on the edges is set by these segments.

The spectral problem for functions $y(x) \in C(\Gamma) \cap C^{2}[\Gamma]$ is determined by a set of equations

$$
-y^{\prime \prime}+q(x) y=\lambda y, \quad x \in \gamma_{k}(k=\overline{1, m}),
$$

on the edges $\gamma_{k}$ with fixed parametrization, equation

$$
-y^{\prime}(\pi / 2)_{\gamma_{m}}+\sum_{k=1}^{m-1} y^{\prime}(\pi / 2)_{\gamma_{k}}=0
$$

in the node $\xi$ and the boundary conditions

$$
y^{\prime}(0)_{\gamma_{k}}-h y(0)_{\gamma_{k}}=0(k=\overline{1, m-1}), \quad y^{\prime}(\pi)_{\gamma_{m}}+H y(\pi)_{\gamma_{m}}=0 .
$$

Where $\lambda$ is the spectral parameter, $q(x), h, H(H>0)$ are real, $q(x) \in C(\Gamma)$ and $q(x)_{\gamma_{1}}=$ $q(x)_{\gamma_{2}}=\ldots=q(x)_{\gamma_{m-1}}$ (this representation of the function $q(x)$ essentially simplifies the technical calculations and does not affect essentially on the study); the symbol $\theta(x)_{\gamma}$ meant a narrowing of the function $\theta(x)$ on the edge $\gamma$. Ratios (1), (2) call the equation on the graph $\Gamma$.

In the future, we will be necessary the equation that take place for functions $z(x) \in$ $C^{1}[0, \pi] \cap C^{2}(0, \pi):$

$$
-z^{\prime \prime}+Q(x) z=\lambda z
$$

where

$$
\begin{aligned}
& Q(x)=q(x)_{\gamma_{1}}, x \in[0, \pi / 2), \\
& Q(x)=q(x)_{\gamma_{m}}, x \in[\pi / 2, \pi] .
\end{aligned}
$$

The solution of the equation (4) will be called any function $z(x) \in C^{1}[0, \pi] \cap C^{2}(0, \pi)$ that satisfies the ratio (4), (5).

Here's the following statement [9].

Theorem 1. For any number $z_{0}, z_{0}^{\prime}$ the equation (4) has the only solution $z(x, \lambda) \in$ $C^{1}[0, \pi] \cap C^{2}(0, \pi)$ satisfying the conditions $z(0, \lambda)=z_{0}, z^{\prime}(0, \lambda)=z_{0}^{\prime}$, which for each fixed $x \in[0, \pi]$ is a entire analytical function by $\lambda$.

Definition. The reverse problem for the system (1)-(3) is to restore potential $q(x)$ and coefficients $h, H$ according to some information about the spectral data of the boundaryvalue problem (1)-(3). 
The concept of spectral data of the boundary-value problem (1)-(3) includes the set of its eigenvalues and norms of eigenfunctions of this problem.

Let functions $\mu(x, \lambda), \eta(x, \lambda) \in C^{1}[0, \pi] \cap C^{2}(0, \pi)$ are equation solutions (4) that satisfy the initial conditions $\mu(\pi / 2, \lambda)=1, \mu^{\prime}(\pi / 2, \lambda)=0, \eta(\pi / 2, \lambda)=0, \eta^{\prime}(\pi / 2, \lambda)=1$, and functions $u(x, \lambda), v(x, \lambda) \in C^{1}[0, \pi] \cap C^{2}(0, \pi)$ are the solutions to the equation (4) with initial conditions $u(0, \lambda)=1, u^{\prime}(0, \lambda)=h, v(\pi, \lambda)=1, v^{\prime}(\pi, \lambda)=-H$. By virtue of the theorem 1 with each fixed $\lambda$ function $u(x, \lambda), v(x, \lambda)$ are a entire analytical function by $\lambda$. Next, let's look at two systems of function $\left\{\varphi_{k}(x, \lambda)\right\}_{1}^{m}$ and $\left\{\hat{\varphi}_{k}(x, \lambda)\right\}_{1}^{m}$ :

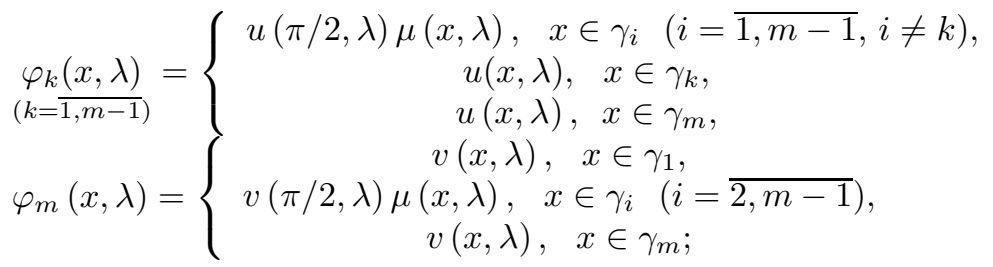

$$
\begin{aligned}
& \hat{\varphi}_{1}(x, \lambda)=\left\{\begin{array}{c}
u(x, \lambda), \quad x \in \gamma_{i}(i=\overline{1, m-1}), \\
(m-1) u^{\prime}(\pi / 2, \lambda) \eta(x, \lambda)+u(\pi / 2, \lambda) \mu(x, \lambda), \quad x \in \gamma_{m},
\end{array}\right. \\
& \begin{array}{c}
\hat{\varphi}_{k}(x, \lambda) \\
(k=\overline{2, m-1})
\end{array}=\left\{\begin{array}{c}
u^{\prime}(\pi / 2, \lambda) \eta(x, \lambda), \quad x \in \gamma_{1}, \\
-\delta_{k i} u^{\prime}(\pi / 2, \lambda) \eta(x, \lambda), \quad x \in \gamma_{i}(i=\overline{2, m}),
\end{array}\right. \\
& \hat{\varphi}_{m}(x, \lambda)=\left\{\begin{array}{c}
\frac{v^{\prime}(\pi / 2, \lambda)}{m-1} \eta(x, \lambda)+v(\pi / 2, \lambda) \mu(x, \lambda), \quad x \in \gamma_{i}(i=\overline{1, m-1}), \\
v(x, \lambda), \quad x \in \gamma_{m} .
\end{array}\right.
\end{aligned}
$$

Obviously, functions $\varphi_{k}(x, \lambda), \hat{\varphi}_{k}(x, \lambda)(k=\overline{1, m})$ are the solutions of the equations (1), (2) and satisfy the following boundary conditions:

$$
\begin{gathered}
\varphi_{k}^{\prime}(0, \lambda)_{\gamma_{k}}-h \varphi_{k}(0, \lambda)_{\gamma_{k}}=0(k=\overline{1, m-1}), \quad \varphi_{m}^{\prime}(\pi, \lambda)_{\gamma_{m}}+H \varphi_{m}(\pi, \lambda)_{\gamma_{m}}=0 \\
\hat{\varphi}_{1}^{\prime}(0, \lambda)_{\gamma_{1}}-h \hat{\varphi}_{1}(0, \lambda)_{\gamma_{1}}=0, \quad \hat{\varphi}_{k}^{\prime}(\pi, \lambda)_{\gamma_{k}}+H \hat{\varphi}_{k}(\pi, \lambda)_{\gamma_{k}}=0(k=\overline{2, m}) .
\end{gathered}
$$

Lemma. Systems $\left\{\varphi_{k}(x, \lambda)\right\}_{1}^{m}$ and $\left\{\hat{\varphi}_{k}(x, \lambda)\right\}_{1}^{m}$ form linearly independent systems of solutions to the equations (1), (2): variety of solutions to the equations (1), (2) $n$-dimensionally, any solution to the equations (1), (2) is a linear combination of functions (6) or functions (7).

The system of function $\left\{\hat{\varphi}_{k}(x, \lambda)\right\}_{1}^{m}$ is convenient under describing the system of eigenfunctions, the system $\left\{\varphi_{k}(x, \lambda)\right\}_{1}^{m}$ to construct the Green's function of boundary value problem (1)-(3).

Let $D(\lambda)=(m-1) u^{\prime}(\pi / 2, \lambda) v(\pi / 2, \lambda)-u(\pi / 2, \lambda) v^{\prime}(\pi / 2, \lambda)$. We denote by $\Omega$ a lot of eigenvalue of the boundary value problem (1)-(3) and let $\Omega^{\prime}, \Omega^{\prime \prime}, \Omega^{\prime \prime \prime}$ is the sets of real numbers $\lambda: \Omega^{\prime}=\{\lambda: D(\lambda)=0, u(\pi / 2, \lambda) \neq 0\}, \Omega^{\prime \prime}=\{\lambda: D(\lambda)=0, u(\pi / 2, \lambda)=0\}$, $\Omega^{\prime \prime \prime}=\{\lambda: D(\lambda) \neq 0, u(\pi / 2, \lambda)=0\}$.

Theorem 2. Eigenvalues and eigenfunctions of the boundary value problem (1)-(3) are real. Eigenfunctions that correspond to different eigenvalues are orthogonal in $L_{2}(\Gamma)$. There is a ratio

$$
\Omega=\Omega^{\prime} \cup \Omega^{\prime \prime} \cup \Omega^{\prime \prime \prime}
$$

$\left(\Omega^{\prime}, \Omega^{\prime \prime}, \Omega^{\prime \prime \prime}\right.$ do not have common elements $)$, in addition: 1) if eigenvalue $\lambda_{n}=\lambda_{n}^{\prime} \in \Omega^{\prime}$, then it is simple; 2) if $\lambda_{n}=\lambda_{n}^{\prime \prime} \in \Omega^{\prime \prime}$, his multiplicity is equal $m-1$; 3) if $\lambda_{n}=\lambda_{n}^{\prime \prime \prime} \in \Omega^{\prime \prime \prime}$, his multiplicity is $m-2$.

The formulated theorem is a special case of the theorem 4 of the work [9]. 
Beginning which the statements of theorem 2, we will assume: $\left\{\lambda_{n}\right\}_{n \geqslant 0}$ if sequence of eigenvalue of the boundary value problem (1)-(3), $\left\{\varphi\left(x, \lambda_{n}\right)\right\}_{n \geqslant 0}$ its corresponding orthogonal system of eigenfunctions. In addition, the eigenvalues are ordered by the increase of their modules and every eigenvalue in the sequence $\left\{\lambda_{n}\right\}_{n \geqslant 0}$ is repeated as many times as it corresponds to the linearly independent eigenfunctions.

The asymptomatic behavior of the functions that define the linearly independent systems of solutions of the equations (1), (2) in a complex $\lambda$-plane of spectral parameter, is set by analogy with the reasoning of the work $[9$, theorem 6$]$. Let $\lambda=\rho^{2}, \tau=\operatorname{Im} \rho$ and $G_{\delta}=\{\rho:|\rho-k| \geqslant \delta>0, k=0,1,2, \ldots\}$.

Theorem 3. The following asymptomatic formulas are correct for $|\rho| \rightarrow+\infty$ :

$$
\begin{aligned}
& \mu(x, \lambda)=\cos \rho\left(\frac{\pi}{2}-x\right)+\mathrm{O}\left(\frac{\exp (|\tau| x)}{|\rho|}\right), \\
& \mu^{\prime}(x, \lambda)=\rho \sin \rho\left(\frac{\pi}{2}-x\right)+\mathrm{O}(\exp (|\tau| x)), \\
& \eta(x, \lambda)=-\frac{1}{\rho} \sin \rho\left(\frac{\pi}{2}-x\right)+\mathrm{O}\left(\frac{\exp (|\tau| x)}{|\rho|^{2}}\right), \\
& \eta^{\prime}(x, \lambda)=\cos \rho\left(\frac{\pi}{2}-x\right)+\mathrm{O}\left(\frac{\exp (|\tau| x)}{|\rho|}\right), \\
& u(x, \lambda)=\cos \rho x+\mathrm{O}\left(\frac{\exp (|\tau| x)}{|\rho|}\right), \\
& u^{\prime}(x, \lambda)=-\rho \sin \rho x+\mathrm{O}(\exp (|\tau| x)), \\
& v(x, \lambda)=\cos \rho(\pi-x)+\mathrm{O}\left(\frac{\exp (|\tau| x)}{|\rho|}\right), \\
& v^{\prime}(x, \lambda)=\rho \sin \rho(\pi-x)+\mathrm{O}(\exp (|\tau| x)),
\end{aligned}
$$

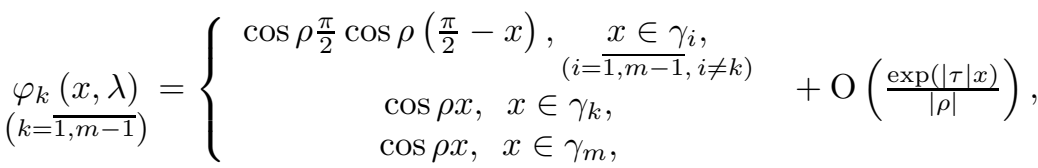

$$
\begin{aligned}
& \varphi_{m}(x, \lambda)=\left\{\begin{array}{c}
\cos \rho(\pi-x), \quad x \in \gamma_{1}, \\
\cos \rho \frac{\pi}{2} \cos \rho\left(\frac{\pi}{2}-x\right), \underset{(i=\overline{2, m-1})}{x \in \gamma_{i},}+\mathrm{O}\left(\frac{\exp (|\tau| x)}{|\rho|}\right), \\
\cos \rho(\pi-x), \quad x \in \gamma_{m},
\end{array}\right. \\
& \underset{k}{\varphi_{k}^{\prime}(x, \lambda)}=\left\{\begin{array}{c}
\rho \cos \rho \frac{\pi}{2} \sin \rho\left(\frac{\pi}{2}-x\right), \quad x \in \gamma_{i}, \\
-\rho \sin \rho x, \quad x \in \gamma_{k}, \\
-\rho \sin \rho x, \quad x \in \gamma_{m},
\end{array} \quad+\mathrm{O}(\exp (|\tau| x)),\right. \\
& \varphi_{m}^{\prime}(x, \lambda)=\left\{\begin{array}{c}
\rho \sin \rho(\pi-x), \quad x \in \gamma_{1}, \\
\rho \cos \rho \frac{\pi}{2} \sin \rho\left(\frac{\pi}{2}-x\right), \underset{(i=\overline{2, m-1})}{x \in \gamma_{i},} \quad+\mathrm{O}(\exp (|\tau| x)), \\
\rho \sin \rho(\pi-x), \quad x \in \gamma_{m},
\end{array}\right. \\
& \Delta_{k}(\lambda)=\rho \sin \rho \pi\left\{\begin{array}{c}
1 / 2, \quad k=\overline{2, m-1}, \\
1, \quad k=1, m,
\end{array} \quad+\mathrm{O}(\exp (|\tau| x)), \rho \in G_{\delta},\right. \\
& D(\lambda)=-\frac{1}{2} m \rho \sin \rho \pi+\mathrm{O}(\exp (|\tau| x)), \rho \in G_{\delta} .
\end{aligned}
$$


Next, the set $\Omega$ can be written in the form $\Omega=\Omega_{1} \cup \Omega_{2}, \Omega_{1}=\Omega^{\prime} \cup \Omega^{\prime \prime}, \Omega_{2}=\Omega^{\prime \prime} \cup \Omega^{\prime \prime \prime}$. Every from set $\Omega_{\ell}$ contain a infinite set of eigenvalues $\left\{\lambda_{n}^{\ell}\right\}_{n \geqslant 0}, \ell=1,2$.

Theorem 4. The function $D(\lambda)$ is uniquely defined by a set of eigenvalues $\left\{\lambda_{n}^{1}\right\}_{n \geqslant 0}$ $\left(\lambda_{n}^{1} \in \Omega_{1}\right)$ :

$$
D(\lambda)=\frac{m \pi}{2}\left(\lambda_{0}^{1}-\lambda\right) \prod_{n=1}^{\infty} \frac{\lambda_{n}^{1}-\lambda}{n^{2}} .
$$

Proof. The function $D(\lambda)$ is a entire function by $\lambda$ of order $\frac{1}{2}$ and, consequently, according to the Hadamard's theorem $D(\lambda)$ is uniquely defined by their zeros $\left\{\lambda_{n}^{1}\right\}_{n \geqslant 0}$ with precision to a constant multiplier:

$$
D(\lambda)=C \prod_{n=1}^{\infty}\left(1-\frac{\lambda}{\lambda_{n}^{1}}\right)
$$

(case $D(0)=0$ can be avoided by shifting the spectrum of the boundary value problem (1)-(3)). We'll consider the function

$$
D^{*}(\lambda)=-\rho \sin \rho \pi=-\lambda \pi \prod_{n=1}^{\infty}\left(1-\frac{\lambda}{n^{2}}\right),
$$

then

$$
\frac{D(\lambda)}{D^{*}(\lambda)}=C \frac{\lambda-\lambda_{0}^{1}}{\lambda_{0}^{1} \pi \lambda} \prod_{n=1}^{\infty} \frac{n^{2}}{\lambda_{n}^{1}} \prod_{n=1}^{\infty}\left(1+\frac{\lambda_{n}^{1}-n^{2}}{n^{2}-\lambda}\right) .
$$

Constant $C$ is determined when passage to the limit in the last ratio at $\lambda \rightarrow-\infty$ :

$$
C=\pi \lambda_{0}^{1} \frac{m}{2} \prod_{n=1}^{\infty} \frac{\lambda_{n}^{1}}{n^{2}}
$$

which leads to (8).

$\mathrm{R}$ e m a r k 1. Similarly, it is shown that a function $u\left(\frac{\pi}{2}, \lambda\right)$ is uniquely defined by a set of eigenvalues $\left\{\lambda_{n}^{2}\right\}_{n \geqslant 0}\left(\lambda_{n}^{2} \in \Omega_{2}\right)$.

Let's define on functions $y(x) \in C^{2}[\Gamma]$ a generalized differential expression of ratios:

$$
\Lambda y=\left\{\begin{array}{c}
-y^{\prime \prime}+q(x) y, \quad x \in \gamma_{k} \quad(k=\overline{1, m}), \\
y^{\prime}(\pi / 2)_{\gamma_{m}}-\sum_{k=1}^{m-1} y^{\prime}(\pi / 2)_{\gamma_{k}}, \quad x \in \xi(x=\pi / 2) .
\end{array}\right.
$$

The Green's function of the boundary value problem (1)-(3) we shall call a function $G(x, t, \lambda)$ such that the solution of a problem $\Lambda y-\lambda y=f(x)$ that meets the boundary conditions (3), in any function $f(x)$ can be presented in the form

$$
y(x, \lambda)=\int_{\Gamma} G(x, t, \lambda) f(t) d t .
$$

Let

$$
\begin{gathered}
\delta(\lambda)=\langle u(x, \lambda), v(x, \lambda)\rangle=\left|\begin{array}{cc}
u(\pi / 2, \lambda) & v(\pi / 2, \lambda) \\
u^{\prime}(\pi / 2, \lambda) & v^{\prime}(\pi / 2, \lambda)
\end{array}\right|, \\
\Delta_{k}(\lambda)=\left\langle\varphi_{k}(x, \lambda), \varphi_{m}(x, \lambda)\right\rangle_{\gamma_{k}}(k=\overline{1, m-1}), \\
\Delta_{m}(\lambda)=\left\langle\varphi_{1}(x, \lambda), \varphi_{m}(x, \lambda)\right\rangle_{\gamma_{m}} .
\end{gathered}
$$


Accordingly to with the views $(6)$ functions $\varphi_{k}(x, \lambda)$ we have

$$
\Delta_{1}(\lambda)=\delta(\lambda), \Delta_{k}(\lambda)=-v(\pi / 2, \lambda) u^{\prime}(\pi / 2, \lambda)(k=\overline{2, m-1})
$$

and because the functions $\varphi_{1}(x, \lambda), \varphi_{m}(x, \lambda)$ satisfy the conditions of agreement $(2)$ in the node $\xi$, then

$$
\Delta_{m}(\lambda)=\langle u(x, \lambda), v(x, \lambda)\rangle_{x=\pi / 2}=\delta(\lambda) .
$$

Let's $G(x, t, \lambda)$ determine the ratio $G(x, t, \lambda)=G_{0}(x, t, \lambda)+g(x, \lambda)$, where

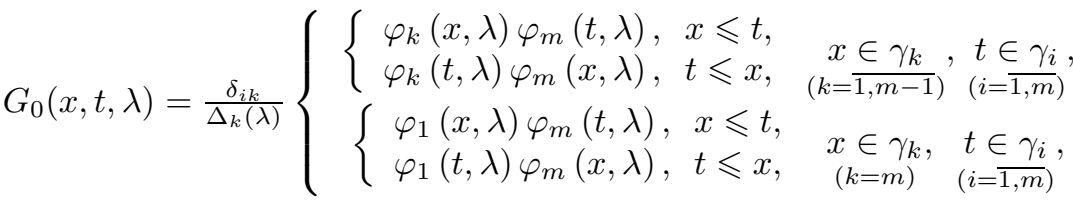

$$
\begin{aligned}
& g(x, \lambda)_{\gamma_{k}}=c_{k} \varphi_{k}(x, \lambda), \quad k=\overline{1, m},
\end{aligned}
$$

and, granting the continuity of the solution $y(x, \lambda)$ on $\Gamma$ and the ratio $(2)$ in the node $\xi$, $c_{k}(k=\overline{1, m})$ are defined as the solution of the system of linear algebraic equations

$$
\left\{\begin{array}{l}
u_{k}(\pi / 2, \lambda) c_{k}-v(\pi / 2, \lambda) c_{m} \underset{(k=1, m-1}{=} G_{0}(x, t, \lambda)_{x=\pi / 2 \in \gamma_{m}}-G_{0}(x, t, \lambda)_{x=\pi / 2 \in \gamma_{k}}, \\
\sum_{k=1}^{m-1} u_{k}^{\prime}(\pi / 2, \lambda) c_{k}-v^{\prime}(\pi / 2, \lambda) c_{m}=\frac{\partial G_{0}}{\partial x}(x, t, \lambda)_{x=\pi / 2 \in \gamma_{m}}-\sum_{k=1}^{m-1} \frac{\partial G_{0}}{\partial x}(x, t, \lambda)_{x=\pi / 2 \in \gamma_{k}} .
\end{array}\right.
$$

The determinant of system is equals $[u(\pi / 2, \lambda)]^{m-2} D(\lambda)$; coefficients $c_{k} \equiv c_{k}(t, \lambda), t \in \Gamma$ $(k=\overline{1, m})$, granting the view $\Delta_{k}(\lambda)(k=\overline{1, m})$, are determined by the following ratios:

under $t \in \gamma_{1}$ :

$$
\begin{gathered}
c_{1}(t, \lambda)=-\frac{(m-2) v^{2}(\pi / 2, \lambda) u^{\prime}(\pi / 2, \lambda)}{\Delta_{1}(\lambda) u(\pi / 2, \lambda) D(\lambda)} \varphi_{1}(t, \lambda), \\
c_{k}(t, \lambda)=-\frac{v(\pi / 2, \lambda)}{u(\pi / 2, \lambda) D(\lambda)} \varphi_{1}(t, \lambda) \quad(k=\overline{2, m-1}), \\
c_{m}(t, \lambda)=-\frac{1}{D(\lambda)} \varphi_{1}(t, \lambda),
\end{gathered}
$$

under $t \in \gamma_{2}$ :

$$
\begin{gathered}
c_{k}(t, \lambda)=-\frac{v(\pi / 2, \lambda)}{u(\pi / 2, \lambda) D(\lambda)} \varphi_{2}(t, \lambda)(k=\overline{1, m-1}, k \neq 2), \\
c_{2}(t, \lambda)=-\frac{v(\pi / 2, \lambda) \widehat{D(\lambda)}}{\Delta_{2}(\lambda) u(\pi / 2, \lambda) D(\lambda)} \varphi_{2}(t, \lambda), \\
c_{m}(t, \lambda)=-\frac{1}{D(\lambda)} \varphi_{2}(t, \lambda),
\end{gathered}
$$

under $t \in \gamma_{m-1}$ :

$$
\begin{gathered}
c_{k}(t, \lambda)=-\frac{v(\pi / 2, \lambda)}{u(\pi / 2, \lambda) D(\lambda)} \varphi_{m-1}(t, \lambda)(k=\overline{1, m-1}, k \neq m-2), \\
c_{m-2}(t, \lambda)=-\frac{v(\pi / 2, \lambda) \widehat{D(\lambda)}}{\Delta_{m-1}(\lambda) u(\pi / 2, \lambda) D(\lambda)} \varphi_{m-1}(t, \lambda),
\end{gathered}
$$




$$
c_{m}(t, \lambda)=-\frac{1}{D(\lambda)} \varphi_{m-1}(t, \lambda)
$$

under $t \in \gamma_{m}$ :

$$
\begin{gathered}
c_{k}(t, \lambda)=-\frac{1}{D(\lambda)} \varphi_{m}(t, \lambda)(k=\overline{1, m-1}), \\
c_{m}(t, \lambda)=-\frac{(m-2) u(\pi / 2, \lambda) u^{\prime}(\pi / 2, \lambda)}{\Delta_{m}(\lambda) D(\lambda)} \varphi_{m}(t, \lambda),
\end{gathered}
$$

here $\widehat{D(\lambda)}=(m-2) u^{\prime}(\pi / 2, \lambda) v(\pi / 2, \lambda)-u(\pi / 2, \lambda) v^{\prime}(\pi / 2, \lambda)$.

Thus if $\lambda$ not zero for $[u(\pi / 2, \lambda)]^{m-2} D(\lambda)$, the Green's function of the boundary value problem (1)-(3) takes the form

$$
G(x, t, \lambda)=G_{0}(x, t, \lambda)+c_{k}(t, \lambda) \varphi_{k}(x, \lambda), x \in \gamma_{k} \quad(k=\overline{1, m}) .
$$

The continuity and symmetry of the function $G(x, t, \lambda)$ (see $(9)$ ) by variables $x, t \in \Gamma$ is obvious.

Theorem 5. The system of eigenfunctions $\left\{\varphi\left(x, \lambda_{n}\right)\right\}_{n \geqslant 0}$ of the boundary value problem (1)-(3) is complete and forms a basis in space $L_{2}(\Gamma)$.

Proof of the theorem uses a view of solution of the boundary value problem (1)-(3) using the Green's function, where the right part of the equation (1) contain a arbitrary completely continuous function $f(x)$. In addition uses a contour integral method when calculating it on extended contours. The full proof of the statement of the theorem is presented in [9, theorem 7].

Next, get over to the proof of the main statement - the uniqueness of solution of the inverse problem (1)-(3).

Let $L(q(x), h, H)$ is the boundary value problem (1)-(3). Let's agree that along with the boundary value problem $L(q(x), h, H)$ is consider the problem $L(\tilde{q}(x), \tilde{h}, \tilde{H})$ the same form, but with other input data. If certain symbol $\chi$ means a object of problem $L(q(x), h, H)$, then symbol $\tilde{\chi}$ will denote by a analogous object relating to the problem $L(\tilde{q}(x), \tilde{h}, \tilde{H})$. From the theorem 4 follows that $D(\lambda)=\widehat{D(\lambda)}, u(\pi / 2, \lambda)=\tilde{u}(\pi / 2, \lambda)$. Let, as above, $\left\{\lambda_{n}\right\}_{n \geqslant 0}$ if a set of eigenvalues of the problem (1)-(3) and $\left\{\omega_{n}\right\}_{n \geqslant 0}$ it corresponds to the sequence $\varphi\left(x, \lambda_{n}\right): \omega_{n}=\int_{\Gamma} \varphi^{2}\left(x, \lambda_{n}\right) d x \quad(n=0,1, \ldots)$.

Theorem 6. The inverse problem (1)-(3) has the unique solution: if the spectral characteristics $\left\{\lambda_{n}\right\}_{n \geqslant 0},\left\{\omega_{n}\right\}_{n \geqslant 0}$ of problems $L(q(x), h, H)$ and $L(\tilde{q}(x), \tilde{h}, \tilde{H})$ coincide, then $L(q(x), h, H)=L(\tilde{q}(x), \tilde{h}, \tilde{H})$, i. e. $q(x)=\tilde{q}(x)$ almost everywhere on $\Gamma$ and $h=$ $\tilde{h}, H=\tilde{H}$.

Proof. The approach used here belongs to N. Levinson. The approach based on the contour integral method when calculating it on extended contours. In what follows the method was improved, thanks first of all to fundamental work [8]. With evidence we rely on the reasoning of theorems 7 and 8 work [9].

Let $f(x)$ is arbitrary absolutely continuous on $\Gamma$ function. We consider the function $Y(x, \lambda), x \in \Gamma$, where

$$
\begin{aligned}
Y(x, \lambda)_{\gamma_{1}} & =\frac{1}{\lambda}\left\{\frac { 1 } { \Delta _ { 1 } ( \lambda ) } \left(\varphi_{m}(x, \lambda) \int_{0}^{x}\left[-\tilde{\varphi}_{1}^{\prime \prime}(t, \lambda)+\tilde{q}(t) \tilde{\varphi}_{1}(t, \lambda)\right] f(t) d t+\right.\right. \\
& +\varphi_{1}(x, \lambda) \int_{x}^{\pi / 2}\left[-\tilde{\varphi}_{m}^{\prime \prime}(t, \lambda)+\tilde{q}(t) \tilde{\varphi}_{m}(t, \lambda)\right] f(t) d t-
\end{aligned}
$$




$$
\begin{aligned}
& \left.-\frac{(m-2) u^{\prime}(\pi / 2, \lambda) v^{2}(\pi / 2, \lambda)}{u(\pi / 2, \lambda) D(\lambda)} \varphi_{1}(x, \lambda) \int_{\gamma_{1}}\left[-\tilde{\varphi}_{1}^{\prime \prime}(t, \lambda)+\tilde{q}(t) \tilde{\varphi}_{1}(t, \lambda)\right] f(t) d t\right)- \\
& -\frac{v(\pi / 2, \lambda)}{u(\pi / 2, \lambda) D(\lambda)} \varphi_{1}(x, \lambda) \sum_{k=2}^{m-1} \int_{\gamma_{k}}\left[-\tilde{\varphi}_{k}^{\prime \prime}(t, \lambda)+\tilde{q}(t) \tilde{\varphi}_{k}(t, \lambda)\right] f(t) d t- \\
& \left.-\frac{1}{D(\lambda)} \varphi_{1}(x, \lambda) \int_{\gamma_{m}}\left[-\tilde{\varphi}_{m}^{\prime \prime}(t, \lambda)+\tilde{q}(t) \tilde{\varphi}_{m}(t, \lambda)\right] f(t) d t\right\}, \\
& Y(x, \lambda)_{\gamma_{2}}=\frac{1}{\lambda}\left\{-\frac{v(\pi / 2, \lambda)}{u(\pi / 2, \lambda) D(\lambda)} \varphi_{2}(x, \lambda) \sum_{\substack{k=1 \\
(k \neq 2)}}^{m-1} \int_{\gamma_{k}}\left[-\tilde{\varphi}_{k}^{\prime \prime}(t, \lambda)+\tilde{q}(t) \tilde{\varphi}_{k}(t, \lambda)\right] f(t) d t+\right. \\
& +\frac{1}{\Delta_{2}(\lambda)}\left(\varphi_{m}(x, \lambda) \int_{0}^{x}\left[-\tilde{\varphi}_{2}^{\prime \prime}(t, \lambda)+\tilde{q}(t) \tilde{\varphi}_{2}(t, \lambda)\right] f(t) d t+\right. \\
& +\varphi_{2}(x, \lambda) \int_{x}^{\pi / 2}\left[-\tilde{\varphi}_{m}^{\prime \prime}(t, \lambda)+\tilde{q}(t) \tilde{\varphi}_{m}(t, \lambda)\right] f(t) d t- \\
& \left.-\frac{v(\pi / 2, \lambda) \widehat{D(\lambda)}}{u(\pi / 2, \lambda) D(\lambda)} \varphi_{2}(x, \lambda) \int_{\gamma_{2}}\left[-\tilde{\varphi}_{2}^{\prime \prime}(t, \lambda)+\tilde{q}(t) \tilde{\varphi}_{2}(t, \lambda)\right] f(t) d t\right)- \\
& \left.-\frac{1}{D(\lambda)} \varphi_{2}(x, \lambda) \int_{\gamma_{m}}\left[-\tilde{\varphi}_{m}^{\prime \prime}(t, \lambda)+\tilde{q}(t) \tilde{\varphi}_{m}(t, \lambda)\right] f(t) d t\right\} \\
& Y(x, \lambda)_{\gamma_{m}}=\frac{1}{\lambda}\left\{-\frac{1}{D(\lambda)} \varphi_{m}(x, \lambda) \sum_{k=1}^{m-1} \int_{\gamma_{k}}\left[-\tilde{\varphi}_{k}^{\prime \prime}(t, \lambda)+\tilde{q}(t) \tilde{\varphi}_{k}(t, \lambda)\right] f(t) d t+\right. \\
& +\frac{1}{\Delta_{m}(\lambda)}\left(\varphi_{m}(x, \lambda) \int_{\pi / 2}^{x}\left[-\tilde{\varphi}_{1}^{\prime \prime}(t, \lambda)+\tilde{q}(t) \tilde{\varphi}_{1}(t, \lambda)\right] f(t) d t+\right. \\
& +\varphi_{1}(x, \lambda) \int_{x}^{\pi}\left[-\tilde{\varphi}_{m}^{\prime \prime}(t, \lambda)+\tilde{q}(t) \tilde{\varphi}_{m}(t, \lambda)\right] f(t) d t- \\
& \left.\left.-\frac{(m-2) u(\pi / 2, \lambda) u^{\prime}(\pi / 2, \lambda)}{D(\lambda)} \varphi_{m}(x, \lambda) \int_{\gamma_{m}}\left[-\tilde{\varphi}_{m}^{\prime \prime}(t, \lambda)+\tilde{q}(t) \tilde{\varphi}_{m}(t, \lambda)\right] f(t) d t\right)\right\},
\end{aligned}
$$

where, as above, $Y(x, \lambda)_{\gamma}$ is a narrowing on the edge $\gamma$. 
Considering the view (6) of functions $\varphi_{k}(x, \lambda)$ in the form of function $Y(x, \lambda), x \in \Gamma$, we will calculate the integrals by parts containing the second derivatives from $\tilde{\varphi}_{k}(x, \lambda)$ :

$$
Y(x, \lambda)_{\Gamma}=\frac{f(x)}{\lambda}+\frac{1}{\lambda}\left(S_{1}(x, \lambda)+S_{2}(x, \lambda)\right) .
$$

In $(10)$

$$
\begin{aligned}
& S_{1}(x, \lambda)_{\gamma_{1}}=\frac{1}{\Delta_{1}(\lambda)}\left\{\varphi_{m}(x, \lambda) \int_{0}^{x} \tilde{\varphi}_{1}^{\prime}(t, \lambda) f^{\prime}(t) d t+\right. \\
& \left.+\varphi_{1}(x, \lambda) \int_{x}^{\pi / 2} \tilde{\varphi}_{m}^{\prime}(t, \lambda) f^{\prime}(t) d t-\frac{(m-2) u^{\prime}(\pi / 2, \lambda) v^{2}(\pi / 2, \lambda)}{u(\pi / 2, \lambda) D(\lambda)} \varphi_{1}(x, \lambda) \int_{\gamma_{1}} \tilde{\varphi}_{1}^{\prime}(t, \lambda) f^{\prime}(t) d t\right\}- \\
& -\frac{v(\pi / 2, \lambda)}{u(\pi / 2, \lambda) D(\lambda)} \varphi_{1}(x, \lambda) \sum_{k=2}^{m-1} \int_{\gamma_{k}} \tilde{\varphi}_{k}^{\prime}(t, \lambda) f^{\prime}(t) d t-\frac{1}{D(\lambda)} \varphi_{1}(x, \lambda) \int_{\gamma_{m}} \tilde{\varphi}_{m}^{\prime}(t, \lambda) f^{\prime}(t) d t, \\
& \underset{\left(i=\frac{2, m-1}{S_{1}}\right)}{S_{1}(x, \lambda)_{\gamma_{i}}}=\frac{1}{\Delta_{i}(\lambda)}\left\{\varphi_{m}(x, \lambda) \int_{0}^{x} \tilde{\varphi}_{i}^{\prime}(t, \lambda) f^{\prime}(t) d t+\right. \\
& \left.+\tilde{\varphi}_{i}(x, \lambda) \int_{x}^{\pi / 2} \tilde{\varphi}_{m}^{\prime}(t, \lambda) f^{\prime}(t) d t-\frac{v(\pi / 2, \lambda) \widehat{D(\lambda)}}{u(\pi / 2, \lambda) D(\lambda)} \varphi_{i}(x, \lambda) \int_{\gamma_{i}} \tilde{\varphi}_{i}^{\prime}(t, \lambda) f^{\prime}(t) d t\right\}- \\
& -\frac{v(\pi / 2, \lambda)}{u(\pi / 2, \lambda) D(\lambda)} \varphi_{i}(x, \lambda) \sum_{\substack{k=1 \\
(k \neq i)}}^{m-1} \int_{\gamma_{k}} \tilde{\varphi}_{k}^{\prime}(t, \lambda) f^{\prime}(t) d t-\frac{1}{D(\lambda)} \varphi_{i}(x, \lambda) \int_{\gamma_{m}} \tilde{\varphi}_{m}^{\prime}(t, \lambda) f^{\prime}(t) d t, \\
& S_{1}(x, \lambda)_{\gamma_{m}}=\frac{1}{\Delta_{m}(\lambda)}\left\{\varphi_{m}(x, \lambda) \int_{\pi / 2}^{x} \tilde{\varphi}_{1}^{\prime}(t, \lambda) f^{\prime}(t) d t+\right. \\
& \left.+\tilde{\varphi}_{1}(x, \lambda) \int_{x}^{\pi} \tilde{\varphi}_{m}^{\prime}(t, \lambda) f^{\prime}(t) d t-\frac{(m-2) u(\pi / 2, \lambda) u^{\prime}(\pi / 2, \lambda)}{D(\lambda)} \varphi_{m}(x, \lambda) \int_{\gamma_{m}} \tilde{\varphi}_{m}^{\prime}(t, \lambda) f^{\prime}(t) d t\right\}- \\
& -\frac{1}{D(\lambda)} \varphi_{m}(x, \lambda) \sum_{k=1}^{m-1} \int_{\gamma_{k}} \tilde{\varphi}_{k}^{\prime}(t, \lambda) f^{\prime}(t) d t
\end{aligned}
$$

the function $S_{2}(x, \lambda)_{\Gamma}$ is represented by the remaining summands $Y(x, \lambda)_{\Gamma}$ that do not contain derivatives $\tilde{\varphi}_{k}^{\prime}(t, \lambda)(k=\overline{1, m})$. The asymptomatic formulas for functions $\tilde{\varphi}_{k}(t, \lambda)(k=\overline{1, m})$ are the same as those of functions $\varphi_{k}(t, \lambda)(k=\overline{1, m})$ (statements of the theorem 3), therefore for the function $S_{2}(x, \lambda)_{\Gamma}$ take place estimate

$$
\max _{x \in \Gamma}\left|S_{2}(x, \lambda)\right| \leqslant \frac{C}{|\rho|}, \quad \rho \in G_{\delta}, \quad|\rho| \geqslant \rho^{*}
$$

under fixed $\delta>0$ and large enough $\rho^{*}>0$. 
We consider the function $S_{1}(x, \lambda)_{\Gamma}$. Let $g(x)=f^{\prime}(x), x \in \Gamma$ (derivatives in the node $\xi$ one-sided). Suppose at first that $g(x)$ it is absolutely continuous on each of the edges $\gamma_{k} \quad(k=\overline{1, m})$. Then integration by piece reduce $S_{1}(x, \lambda)$ to a view containing only a function $g(x)$ under the derivative sign. Because of the asymptotic formulas by theorem 3 get a estimate (11):

$$
\max _{x \in \Gamma}\left|S_{1}(x, \lambda)\right| \leqslant \frac{C}{|\rho|}, \quad \rho \in G_{\delta}, \quad|\rho| \geqslant \rho^{*} .
$$

Let now $g(x) \in L(\Gamma)$. We will fix $\varepsilon>0$ and choose a absolutely continuous function so that

$$
\int_{\Gamma}\left|g(t)-g_{\varepsilon}(t)\right| d t<\frac{\varepsilon}{2 C^{0}},
$$

where $C^{0}=\max _{x \in \Gamma} \sup _{\rho \in G_{\delta}}\left|S_{1}(x, \lambda)\right|$. Then at $\rho \in G_{\delta}, \rho \geqslant \rho^{*}$ we have

$$
\max _{x \in \Gamma}\left|S_{1}(x, \lambda)\right| \leqslant \max _{x \in \Gamma}\left|S_{1}\left(x, \lambda, q_{\varepsilon}\right)\right|+\max _{\Gamma}\left|S_{1}\left(x, \lambda ; g-g_{\varepsilon}\right)\right| \leqslant \varepsilon / 2+C^{0} /|\rho| \text {. }
$$

Consequently, exist $\rho^{0}>0$ so that $\max _{\Gamma}\left|S_{1}(x, \lambda)\right| \leqslant \varepsilon$ when $\rho>\rho^{0}$. Because of the arbitrariness, we get

$$
\lim _{|\rho| \rightarrow \infty} \max _{x \in \Gamma}\left|S_{1}(x, \lambda)\right|=0, \quad \rho \in G_{\delta} .
$$

We consider the contour integral

$$
I_{N}(x)=\frac{1}{2 \pi i} \int_{R_{N}} Y(x, \lambda) d \lambda,
$$

here $R_{N}=\left\{\lambda:|\lambda|=(N+1 / 2)^{2}\right\}, N \geqslant 1$, is the integer (counter-clockwise bypass). From (12), (13) we get $I_{N}(x)=f(x)+\varepsilon_{N}(x), \lim _{N \rightarrow \infty} \max _{x \in \Gamma}\left|\varepsilon_{N}(x)\right|=0$.

On the other hand, you can calculate the integral $I_{N}(x)$ with the help of theorem of residue:

$$
\begin{gathered}
\operatorname{Res}_{\lambda=\lambda_{n}} Y(x, \lambda)_{\gamma_{1}}=\lim _{\lambda \rightarrow \lambda_{n}}\left(\lambda-\lambda_{n}\right)\left\{\frac { 1 } { \Delta _ { 1 } ( \lambda ) } \left(\varphi_{m}(x, \lambda) \int_{0}^{x} \tilde{\varphi}_{1}(t, \lambda) f(t) d t+\right.\right. \\
\left.+\varphi_{1}(x, \lambda) \int_{x}^{\pi / 2} \tilde{\varphi}_{m}(t, \lambda) f(t) d t-\frac{(m-2) u^{\prime}(\pi / 2, \lambda) v^{2}(\pi / 2, \lambda)}{u(\pi / 2, \lambda) D(\lambda)} \varphi_{1}(x, \lambda) \int_{\gamma_{1}} \tilde{\varphi}_{1}(t, \lambda) f(t) d t\right)- \\
\left.-\frac{v(\pi / 2, \lambda)}{u(\pi / 2, \lambda) D(\lambda)} \varphi_{1}(x, \lambda) \sum_{k=2}^{m-1} \int_{\gamma_{k}} \tilde{\varphi}_{k}(t, \lambda) f(t) d t-\frac{1}{D(\lambda)} \varphi_{1}(x, \lambda) \int_{\gamma_{m}} \tilde{\varphi}_{m}(t, \lambda) f(t) d t\right\} \\
\operatorname{Res}_{\lambda=\lambda_{n}} Y(x, \lambda)_{\gamma_{2}}=\lim _{\lambda \rightarrow \lambda_{n}}\left(\lambda-\lambda_{n}\right)\left\{-\frac{v(\pi / 2, \lambda)}{u(\pi / 2, \lambda) D(\lambda)} \varphi_{2}(x, \lambda) \sum_{\substack{k=1 \\
(k \neq 2)}}^{\substack{\gamma_{k}-1 \\
\gamma_{k}}} \tilde{\varphi}_{k}(t, \lambda) f(t) d t+\right.
\end{gathered}
$$




$$
\begin{gathered}
+\frac{1}{\Delta_{2}(\lambda)}\left(\varphi_{m}(x, \lambda) \int_{0}^{x} \tilde{\varphi}_{2}(t, \lambda) f(t) d t+\varphi_{2}(x, \lambda) \int_{x}^{\pi / 2} \tilde{\varphi}_{m}(t, \lambda) f(t) d t-\right. \\
\left.\left.-\frac{v(\pi / 2, \lambda) \widehat{D}(\lambda)}{u(\pi / 2, \lambda) D(\lambda)} \varphi_{2}(x, \lambda) \int_{\gamma_{2}} \tilde{\varphi}_{2}(t, \lambda) f(t) d t\right)-\frac{1}{D(\lambda)} \varphi_{2}(x, \lambda) \int_{\gamma_{m}} \tilde{\varphi}_{m}(t, \lambda) f(t) d t\right\} \\
\ldots \\
\operatorname{Res}_{\lambda=\lambda_{n}} Y(x, \lambda)_{\gamma_{m}}=\lim _{\lambda \rightarrow \lambda_{n}}\left(\lambda-\lambda_{n}\right)\left\{-\frac{1}{D(\lambda)} \varphi_{m}(x, \lambda) \sum_{k=1}^{m-1} \int_{\gamma_{k}} \tilde{\varphi}_{k}(t, \lambda) f(t) d t+\right. \\
+\frac{1}{\Delta_{m}(\lambda)}\left(\varphi_{m}(x, \lambda) \int_{\pi / 2}^{x} \tilde{\varphi}_{1}(t, \lambda) f(t) d t+\varphi_{1}(x, \lambda) \int_{x}^{\tilde{\varphi}_{m}}(t, \lambda) f(t) d t-\right. \\
\left.\left.-\frac{(m-2) u(\pi / 2, \lambda) u^{\prime}(\pi / 2, \lambda)}{D(\lambda)} \varphi_{m}(x, \lambda) \int_{\gamma_{m}} \tilde{\varphi}_{m}(t, \lambda) f(t) d t\right)\right\} .
\end{gathered}
$$

From the conditions of the theorem, as well taking into account the statements of the theorem 5 and using the technique of transforms of expressions $\operatorname{Res}_{\lambda=\lambda_{n}} Y(x, \lambda)_{\gamma_{k}}, k=\overline{1, m}$ (see proof of the theorem 8 of work [9]), we get

$$
I_{N}(x)=\sum_{n=1}^{N} \frac{1}{\alpha_{n}} \varphi\left(x, \lambda_{n}\right) \int_{\Gamma} \tilde{\varphi}\left(t, \lambda_{n}\right) f(t) d t
$$

it means

$$
f(x)=\sum_{n=1}^{\infty} \frac{1}{\alpha_{n}} \varphi\left(x, \lambda_{n}\right) \int_{\Gamma} \tilde{\varphi}\left(t, \lambda_{n}\right) f(t) d t,
$$

here $\alpha_{n}=\int_{\Gamma} \varphi^{2}\left(t, \lambda_{n}\right) d t, \lambda_{n} \in \Omega, \varphi\left(x, \lambda_{n}\right)$ is eigenfunction of the problem $L(q(x), h, H)$, $\tilde{\varphi}\left(t, \lambda_{n}\right)$ is eigenfunction of the problem $L(\tilde{q}(x), \tilde{h}, \tilde{H})$. Together with basis property of $\left\{\varphi\left(x, \lambda_{n}\right)\right\}_{n \geqslant 0}$ in $L^{2}(\Gamma)$ we have $\int_{\Gamma}\left(\varphi\left(t, \lambda_{n}\right)-\tilde{\varphi}\left(t, \lambda_{n}\right)\right) f(t) d t=0$. By virtue of the arbitrariness of the function $f(x)$, we conclude that $\varphi\left(t, \lambda_{n}\right)=\tilde{\varphi}\left(t, \lambda_{n}\right)$ at all $n \geqslant 0$ and $x \in \Gamma$. Consequently, $q(x)=\tilde{q}(x)$ almost everywhere on $\Gamma$ and $h=\tilde{h}, H=\tilde{H}$. The theorem 6 is proven.

$\mathrm{R}$ e $\mathrm{m}$ a $\mathrm{rk} 2$. The results of the study will not change if the boundary conditions $(3)$ are replaced by the terms of Dirichlet $y(0)_{\gamma_{k}}=0(k=\overline{1, m-1}), y(\pi)_{\gamma_{m}}=0$.

The totality of the results of the work [2] (inverse problem with distributed parameters on the simplest graph) and this work, indicates the path of analysis of the inverse spectral problem with distributed parameters on a arbitrary graph. This path is based on the results of one of the authors of the article using the so-called "gluing method" of the linearly independent solutions of differential equations, defined on the subgraphs of this graph $[11,12]$.

Example. In the capacity of a illustration of the results we turn our attention to question the restoration of elastic characteristics by a "mast-stretching" antenna design with one stretching strengthening node to the body of the mast [10, 13]. In addition, the 
mast fragment, which is above the stretching strengthening node, has a mass much smaller than the mass of the rest of the mast, that makes it possible to neglect it in a mathematical description of the process of vibrations of the mast system. If this circumstance is taken into account, then mast fragment above the stretching strengthening node is interpreted as a mass concentrated in the node equal to the mass of that fragment. The mast fragment below the stretching strengthening node experience longitudinal vibrations, and stretching are transverse vibrations.

Let the variety $\Gamma$ is a graph-star with edges $\gamma_{k}(k=\overline{1, m})$ and a node $\xi$; each edge $\gamma_{k}(k=\overline{1, m-1})$ is parameterized by a section $[0, \ell / 2]$, a rib $\gamma_{m}$ is a section $[\ell / 2, \ell]$. The mathematical model of the vibrating process of the mast system is the initial-boundary value problem for the function $u(\zeta, t),(\zeta, t) \in \Gamma \times[0, T]$ consisting of $m$ equations

$$
\frac{\partial^{2} u}{\partial t^{2}}(\zeta, t)=\frac{\partial^{2} u}{\partial \zeta^{2}}(\zeta, t)-q(\zeta) u(\zeta, t) .
$$

On every edge $\gamma_{k}(k=\overline{1, m})$, ratios

$$
u(\ell / 2, t)_{\gamma_{k}}=u(\ell / 2, t)_{\gamma_{m}}, \quad \sum_{k=1}^{m-1} \frac{\partial u(\ell / 2, t)_{\gamma_{k}}}{\partial \zeta}=\frac{\partial u(\ell / 2, t)_{\gamma_{m}}}{\partial \zeta},
$$

in node $\xi$, initial and boundary conditions

$$
\begin{gathered}
u(\zeta, 0)=\tau(\zeta), \quad \frac{\partial u}{\partial t}(\zeta, 0)=\hat{\tau}(\zeta), \\
\frac{\partial u}{\partial \zeta}(0, t)_{\gamma_{k}}-h_{k} u(0, t)_{\Im_{k}}=0, \quad \frac{\partial u}{\partial \zeta}(\ell, t)+H u(\ell, t)=0
\end{gathered}
$$

(function $q(x)$ describes the elastic characteristics of antenna fragments, function $\tau(\zeta)$ and $\hat{\tau}(\zeta)$ determine the initial conditions of the vibrational process, constants $h$ and $H$ characterize the conditions of the stretching strengthening node and body antenna, respectively).

The inverse problem for the system (14)-(17) is to determine the parameters $q(x), h$ и $H$, that characterizes the elastic properties of a "mast-stretching" antenna design. The application of the Fourier method to the problem (14)-(17) and consequent transformations analogous to the transformations of Liouville reduce to a inverse spectral problem (1)-(3) on the graph-star $\Gamma$.

Conclusion. The paper considers the possibility of restoring the Sturm-Liouville operator with distributed parameters on the graph-star on spectral characteristics, using the classic results of the inverse spectral problems [8]. This approach differs essentially from the approaches of the work $[3,4,7]$, which use methods of the theory of boundary control of differential systems. The conditions for the uniqueness solution of the inverse spectral problem on the graph-star are obtained and a example is given, illustrating the use of the obtained results in solving inverse problems for evolutionary equations with distributed parameters on the graph. It should be noted that the obtained results supplement and develop the ideas and research presented in the work [8] when analyzing the inverse problem for the parabolic type equation with distributed parameters on the simplest graph. These and the obtained results indicate the way in which the inverse spectral problems with distributed parameters on arbitrary graph are analyzed. Recent results in the direction of analysis evolutionary systems in network-like domains [14-20] and analysis dynamic systems [21-26] allow the results of this work to be used in the construction of stabilizing 
control effects in complex-joint constructions. It should also be noted that the approach to the analysis of relay control system presented in [27] allow partial use of the results of this work.

\section{References}

1. Provotorov V. V., Podvalny S. L. Opredelenie startovoi funkcii v zadache nabludeniy parabolicheskoi sistemi na grafe [Determining the starting function in the task of observing the parabolic system with distributed parameters on the graph]. Vestnik of Voronezh State Technical University, 2014, vol. 10, no. 6, pp. 29-35. (In Russian)

2. Zhabko A. P., Nurtazina K. B., Provotorov V. V. About one approach to solving the inverse problem for parabolic equation. Vestnik of Saint Petersburg University. Applied Mathematics. Computer Science. Control Processes, 2019, vol. 15, iss. 3, pp. 322-335.

https://doi.org/10.21638/11701/spbu10.2019.303

3. Avdonin S., Murzabekova G., Nurtazina K. Source identification for the differential equation with memory. Trends in Mathematics. Research Perspective. Switzerland, Birkhäeuser Springer International Publishing, 2017, pp. 111-120.

4. Avdonin S., Bell J., Nurtazina K. Determining distributed parameters in a neuronal cable model on a tree graph. Mathematic Methods in the Applied Sciences, 2017, vol. 40, iss. 11, pp. 3973-3991.

5. Podvalny S. L., Provotorov V. V., Podvalny E. S. The controllability of parabolic systems with delay and distributed parameters on the graph. Procedia Computer Sciense. Series "12th International Symposium Intelligent Systems, INTELS 2016”, 2017, pp. 324-330.

6. Karelin V. V. Shtrafnye funkcii v zadache upravleniya processom nabludeniya [Penalty functions in the control problem of an observation process]. Vestnik of Saint Petersburg University. Series 10. Applied Mathematics. Computer Science. Control Processes, 2010, iss. 4, pp. 109-114. (In Russian)

7. Avdonin S., Kurasov P. Inverse problems for quantum trees. Inverse Problems Imag., 2008, vol. 2, iss. 1, pp. 3973-3991.

8. Yurko V. A. Vvedenie v teoriyu obratnih spektral'nih zadach [Introduction to the theory of inverse spectral problems]. Moscow, Fizmatlit Publ., 2007, 384 p. (In Russian)

9. Provotorov V. V. Eigenfunctions of the Sturm-Liouville problem on astar graph. Mathematics, 2008, vol. 199 , no. 10 , pp. 1523-1545.

10. Provotorov V. V. Modelirovanie kolebatelnih processov "machta-rastjagki" [Modeling of vibrating processes of "mast-stretching"]. Systems of Control and Information Technologies, 2008, no. 1.2(31), pp. 272-277. (In Russian)

11. Provotorov V. V. Razlozenie po sobstvennym funkciyam zadachi Shturma-Liuvillya na grafepuchke [Expansion of eigenfunctions of Sturm-Liouville problem on astar graph]. Russian Mathematics, 2008, vol. 3, pp. 50-62. (In Russian)

12. Provotorov V. V. Sobstvennye funkcii zadachi Shturma-Liuvillja na grafe-zvezde [Eigenfunctions of the Sturm-Liouville problem astar graph]. Mathematics, 2008, vol. 199, iss. 10, pp. 105-126. (In Russian)

13. Provotorov V. V. Metod momentov v zadache gasheniy kolebanii differecialnoi sistemi na grafe [The method of moments in the problem of extinguishing the oscillations of the differential system on the graph]. Vestnik of Saint Petersburg University. Series 10. Applied Mathematics. Computer Science. Control Processes, 2010, iss. 2, pp. 60-69. (In Russian)

14. Provotorov V. V., Provotorova E. N. Sintez optimal'nogo granichnogo upravlenija parabolicheskoi sistemy s zapazdyvaniem i raspredelennymi parametrami na grafe [Synthesis of optimal boundary control of parabolic systems with delay and distributed parameters on the graph]. Vestnik of Saint Petersburg University. Applied Mathematics. Computer Science. Control Processes, 2017, vol. 13, iss. 2, pp. 209-224. https://doi.org/10.21638/11701/spbu10.2017.207 (In Russian)

15. Provotorov V. V., Ryazhskikh V. I., Gnilitskaya Yu. A. Unique weak solvability of nonlinear initial boundary value problem with distributed parameters in the netlike domain. Vestnik of Saint Petersburg University. Applied Mathematics. Computer Science. Control Processes, 2017, vol. 13, iss. 3, pp. 264-277. https://doi.org/10.21638/11701/spbu10.2017.304

16. Provotorov V. V. Boundary control of a parabolic system with delay and distributed parameters on the graph. International Conference "Stability and Control Processes" in memory of V. I. Zubov (SCP). Saint Petersburg, Russia, 2015, pp. 126-128.

17. Provotorov V. V., Sergeev S. M., Part A. A. Solvability of hyperbolic systems with distributed parameters on the graph in the weak formulation. Vestnik of Saint Petersburg University. Applied Mathematics. Computer Science. Control Processes, 2019, vol. 14, iss. 1, pp. 107-117.

https://doi.org/10.21638/11701/spbu10.2019.2003 
18. Provotorov V. V., Provotorova E. N. Optimal control of the linearized Navier-Stokes system in a netlike domain. Vestnik of Saint Petersburg University. Applied Mathematics. Computer Science. Control Processes, 2017, vol. 13, iss. 4, pp. 428-441. https://doi.org/10.21638/11701/spbu10.2017.409

19. Artemov M. A., Baranovskii E. S., Zhabko A. P., Provotorov V. V. On a 3D model of nonisothermal flows in a pipeline network. Journal of Physics. Conference Series, 2019, vol. 1203, Article ID 012094. https://doi.org/10.1088/1742-6596/1203/1/012094

20. Zhabko A. P., Provotorov V. V., Balaban O. R. Stabilization of weak solutions of parabolic systems with distributed parameters on the graph. Vestnik of Saint Petersburg University. Applied Mathematics. Computer Science. Control Processes, 2019, vol. 15, iss. 2, pp. 187-198. https://doi.org/10.21638/11701/spbu10.2019.203

21. Zhabko A. P., Tikhomirov O. G., Chizhova O. N. On stabilization of a class of systems with time proportional delay. Vestnik of Saint Petersburg University. Applied Mathematics. Computer Science. Control Processes, 2018, vol. 14, iss. 2, pp. 165-172. https://doi.org/10.21638/11701/spbu10.2018.209

22. Alexandrova I. V., Zhabko A. P. A new LKF approach to stability analysis of linear systems with uncertain delays. Automatica, 2018, vol. 91, pp. 173-178.

23. Aleksandrov A., Aleksandrova E., Zhabko A. Asymptotic stability conditions for certain classes of mechanical systems with time delay. WSEAS Transactions on Systems and Control, 2014, vol. 9, pp. 388-397.

24. Aleksandrov A., Aleksandrova E., Zhabko A. Asymptotic stability conditions of solutions for nonlinear multiconnected time-delay systems. Circuits Systems and Signal Processing, 2016, vol. 35, no. 10, pp. 3531-3554.

25. Zhabko A. P., Tikhomirov O. G., Chizhova O. N. On stabilization of a class of systems with time proportional delay. Vestnik of Saint Petersburg University. Applied Mathematics. Computer Science. Control Processes, 2018, vol. 14, iss. 2, pp. 165-172. https://doi.org/10.21638/11701/spbu10.2018.209

26. Veremey E. I., Sotnikova M. V. Stabilizaciya plazmy na baze prognoza s ustoichivym lineinym priblizheniem [Plasma stabilization by prediction with stable linear approximation]. Vestnik of Saint Petersburg University. Series 10. Applied Mathematics. Computer Science. Control Processes, 2011, iss. 1, pp. 116-133. (In Russian)

27. Kamachkin A. M., Yevstafyeva V. V. Oscillations in a relay control system at an external disturbance. Control Applications of Optimization 2000: Proceedings of the 11th IFAC Workshop, 2000, vol. 2, pp. 459-462.

Received: January 01, 2020.

Accepted: May 28, 2020.

Authors' information:

Aleksei P. Zhabko - Dr. Sci. in Physics and Mathematics, Professor; zhabko.apmath.spbu@mail.ru

Karlygash B. Nurtazina - PhD Sci. in Physics and Mathematics; knurtazina@mail.ru

Vyacheslav V. Provotorov - Dr. Sci. in Physics and Mathematics, Professor; wwprov@mail.ru

\section{Единственность решения обратной спектральной задачи с распределенными параметрами на граф-звезде*}

\section{А. П. Жабко ${ }^{1}$, К. Б. Нуртазина ${ }^{2}$, В. В. Провоторов ${ }^{3}$}

1 Санкт-Петербургский государственный университет, Российская Федерация, 199034, Санкт-Петербург, Университетская наб., 7-9

2 Евразийский национальный университет имени Л. Н. Гумилева, Республика Казахстан, 010008, Нур-Султан, ул. Сатбаева, 2

3 Воронежский государственный университет, Российская Федерация, 394006, Воронеж, Университетская пл., 1

Для цитирования: Zhabko A. P., Murtazina K.B., Provotorov V. V. Uniqueness solution to the inverse spectral problem with distributed parameters on the graph-star // Вестник Санкт-

* Работа выполнена при финансовой поддержке Министерства образования и науки Республики Казахстан (проект № АР05136197). 
Петербургского университета. Прикладная математика. Информатика. Процессы управления. 2020. Т. 16. Вып. 2. С. 129-143. https://doi.org/10.21638/11701/spbu10.2020.205

В пространстве кусочно-гладких на графе-звезде функций изучается вопрос единственности восстановления дифференциального оператора краевой задачи по его спектральным характеристикам, т. е. рассматривается задача единственности восстановления коэффициента в дифференциальном выражении и постоянных в краевых условиях краевой задачи по спектральным данным - множеству собственных значений и множеству норм собственных функций оператора. Особенность оператора краевой задачи порождена структурой графа: дифференциальное выражение определено на внутренних частях всех ребер графа, а во внутреннем узле графа, где оно теряет смысл, имеет место обобщенное условие Кирхгофа - условие согласования (условие сопряжения). Используется спектральный подход, базирующийся на спектральных свойствах эллиптического оператора: аналитичность функции Грина краевой задачи по спектральному параметру, спектральная полнота и базисность множества собственных функций в пространстве интегрируемых с квадратом функций. Полученные результаты являются основой при решении обратных задач для эволюционных дифференциальных систем параболического и гиперболического типов с распределенными параметрами на сети (графе), эллиптическая часть которых содержит коэффициенты, подлежащие определению. В задачах прикладного характера это прежде всего параметры, характеризующие свойства переноса сплошной среды и описывающие упругие свойства процесса деформации среды. Рассмотренный подход может быть применим и к задачам, пространственная переменная которых есть векторная величина, изменяющаяся на сетеподобной области.

Ключевые слова: граф, дифференциальный оператор, спектральные характеристики, обратная спектральная задача, единственность решения.

Контактная информация:

Жабко Алексей Петрович - д-р физ.-мат. наук, проф.; zhabko.apmath.spbu@mail.ru

Нуртазина Карлыгаш Бегахметовна - канд. физ.-мат. наук, доц.; knurtazina@mail.ru

Провоторов Влчеслав Васильевич - д-р физ.-мат. наук, проф.; wwprov@mail.ru 